\title{
Effects of the elderly's oral health status and dental care utilization on their health-related quality of life
}

\author{
Seong Hyeon Chae, Chun-Bae Kim*
}

Department of Preventive Medicine, Yonsei University Wonju College of Medicine, Wonju, Korea

The objective of this study was to investigate the oral health status, dental care utilization and health-related quality of life of elderly living alone to collect basic data on how to improve quality of life using the components of the European Quality of Life-5 dimension (EQ-5D) scale. The study used raw data of the community health survey from 2016 for South Jeolla Province. The data entailed 2,671 elderly people of aged 65 years and above living alone. Statistical analysis was performed by frequency analysis and chi-squared and t-tests. Analysis of variance was performed using multiple regression analysis. The significance level was determined to be 0.05 . Chewing problems and speaking discomfort, oral health examination and unmet dental needs $(p<0.001)$ were all significantly related. In the effect on the components of the EQ-5D by logistic regression analysis, gender, age, education level, economy activity, chewing problems, speaking problem, oral health examination and unmet dental needs were the significant variables in the quality of healthrelated life. The results showed that oral health status and dental care utilization significantly influenced the quality of life in elderly living alone. Through the recognition of the impact of oral health on health-related quality of life, we expect that the data from this study will help promote the development of oral health and oral health education programs for the maintenance and promotion of adult health.

Key Words: Aged, Community health survey, Dental care utilization, European Quality of Life-5 dimension, Oral health status

(c) This is an open-access article distributed under the terms of the Creative Commons Attribution Non-Commercial License (http://creativecommons.org/licenses/by-nc/4.0) which permits unrestricted noncommercial use, distribution, and reproduction in any medium, provided the original work is properly cited.

\section{서 론}

평균수명의 증가로 인해 기대수명 역시 82.3세로 늘어나 노 인의 건강한 삶에 대한 관심이 증가하였다[1]. 건강수명은 73세 로 기대수명보다 약 9.3 세가 낮아 우리나라 노인은 그 기간만 큼 건강하지 못하게 살아가고 있다. 노인의 건강 문제는 대부분 만성질환으로 생활습관 개선 및 자기 건강관리능력이 요구되고 있다[2]. 특히, 구강건강은 전신 건강을 유지하기 위한 중요한 요인으로 작용한다. 이렇듯 치주질환과 치아우식증은 우리나라
만성질환 중 10 위 안에 들어있을 정도로 관리가 요구되고 있다 [3]. 치아우식증과 치주질환은 치료하지 않고 방치할 경우 치아 상실뿐 아니라, 구강질환으로 생긴 장애는 일상생활에 영향을 미치며 기능장애도 가져올 수 있다[4]. 음식 섭취 시 저작 불편 으로 인한 영양공급의 어려움과 발음 불편 등은 전신 건강에 좋 지 못한 영향을 준다[5]. 구강건강 문제는 구강뿐만 아니라 전신 건강, 사회관계, 삶의 만족도 및 자존감 등 여러 요인들과 관련 이 있다. 치아 상실은 저작 능력 저하로 식사의 질과 영양 섭취 균형이 떨어지고 발음 저하 및 심미성에 영향을 주며 불편과 통

Received November 22, 2018; Revised December 5, 2018; Accepted December 26, 2018

Corresponding author: Chun-Bae Kim, Department of Preventive Medicine, Yonsei University Wonju College of Medicine, 20 Ilsan-ro, Wonju 26426, Korea.

Tel: +82-33-741-0344, Fax: +82-33-747-0409, E-mail: kimcb@yonsei.ac.kr

Copyright ๑ 2019, Oral Biology Research Institute 
증 등으로 일상생활에도 영향을 미치게 된다[6].

한편, 가족관계가 변화하면서 65세 이상 노인의 가구 유형이 변화하여 독거가구(33.4\%)와 배우자 동거가구(32.7\%)가 늘어 났고, 자녀와 함께 사는 가구(15.3\%) 비율은 점점 감소하고 있 다[7]. 이러한 변화가 이어진다면 부부중심의 가구가 점점 늘어 나며 배우자 사망 후 독거노인이 증가할 것으로 예상된다. 노인 부양구조 변화는 노인의 행복한 삶을 사는 데 있어 부정적인 영 향을 미치며 이는 건강에도 부정적인 영향을 미치게 된다. 평 균 수명의 연장으로 노인들의 삶은 생존 여부가 아닌 삶의 질 향상이 주요 관심사로 대두되고 있으며[8], 건강 관련 삶의 질 (health related quality of life, HRQoL)과 건강 및 행복에 대한 주제에 관한 논의가 점차 증가하고 있다[9].

$\mathrm{HRQOL}$ 은 개인의 관심사 및 기준, 기대, 삶의 목적과 깊은 관 련을 가지고 있다. 실제 건강과 자신의 삶이 어떠한가에 대하 여 인식하는 것은 개개인의 건강 또는 정신적, 신체적 건강 인식 등에 영향을 받아 자신이 생각하는 주관적인 삶의 질을 뜻하며 [10], 주로 보건의료 결과를 측정하고, 건강상태를 측정하는 데 사용되고 있다[11]. HRQoL을 평가하는 도구 중에서 European Quality of Life-5 dimension (EQ-5D)은 건강상태를 전체적으 로 측정하기 위하여 EuroQol Group에서 만든 HRQoL 지표이 다. 이 건강 관련 삶의 지표는 단순하지만 광범위한 건강상태와 치료를 평가할 수 있으며, 건강조사에도 사용할 수 있도록 되어 있어 HRQOL을 측정하기 위해 많이 사용되는 도구이다. 각각의 나라 문화 상황에 맞게 가중치를 산출하여 EQ-5D를 사용하고 있다[12].

기존의 연구에서는 구강건강과 HRQOL에 대해서 주로 취약 계층 노인을 대상으로 실시하였고, 국가 조사 자료를 이용하여 성인이나 일부 지역 주민만을 대상으로 진행되었다. 독거노인 에 대한 구강건강 상태, 구강건강서비스 이용과 $\mathrm{HRQOL}$ 의 관련 성을 비교한 연구는 거의 없는 상태이다.

본 연구에서는 지역사회에 거주하는 65 세 이상 독거노인의 구강건강 상태, 구강건강서비스 이용과 $\mathrm{HRQOL}$ 과의 관련성을 살펴보고 삶의 질 향상 방안의 기초자료로 활용하고자 하였다.

\section{대상 및 방법}

\section{연구대상}

연구 자료는 2016년 질병관리본부에서 실시한 지역사회건강 조사로서 총 254 개 보건소에서 약 900 명의 표본 크기로 전국 시, 읍, 면, 동, 주택 유형 등을 선정하여 표본지점 및 가구를 추 출하였다. 질병관리본부 연구윤리심의위원회의 승인을 받아 이 용하였다(승인번호: 2016-10-01-P-A). 2016년 8월부터 11월
까지 조사한 전라남도 22 개 시, 군 주민 19,613 명 중 65 세 이상 독거노인 2,671명을 대상으로 최종 분석하였다.

\section{건강 관련 삶의 질(EQ-5D)}

HRQoL은 EuroQol Group이 개발한 EQ-5D 설문을 이용하 였다. EQ-5D는 전반적인 건강을 측정하기 위해 개발된 도구로 HRQoL을 측정할 수 있다. 자기관리(self-care), 운동능력(mobility), 일상활동(usual activities), 불안/우울(anxiety/depression), 통증/불편감(pain/discomfort)의 5 개 문항으로 구성되어 있으며 '많이 문제 있음' '다소 문제 있음', '전혀 문제없음'의 세 단계로 답할 수 있게 되어 있다. 건강상태는 다섯 문항의 측 정값에 대하여 가중치를 구하여 HRQoL 점수인 EQ-5D index 를 구하여 사용한다. 그 값이 죽음보다 못한 건강상태인 경우 -1 점에서 완전한 건강상태를 의미하는 1 점 사이로 분포한다.

\section{구강건강 상태}

주관적 구강건강, 발음 불편, 저작 불편을 독립변수로 선정하 였다. 주관적 구강건강 상태에서는 '나쁨' '보통', '좋음'으로 분 류하였고 발음 및 저작 불편에 대해서는 '예’, '보통', '안 불편 함'으로 분류하였다.

\section{구강건강서비스 이용}

구강건강서비스 이용은 구강검진, 스케일링 경험, 필요 치과 진료 미수진을 독립변수로 선정하였으며, 모두 ‘예', ‘아니오'로 분류하였다.

\section{통계자료 분석}

연구대상자의 인구사회학적 특성, 구강건강 상태, 구강건강 서비스 이용과 HRQoL의 차이는 카이제곱 검정과 one way ANOVA로 분석하였다. 사후 검정으로 Scheffe test를 실시 하였다. 일반적 특성, 구강건강 상태, 구강건강서비스 이용과 $\mathrm{HRQOL}$ 간의 상관관계는 피어슨 상관관계(Pearson's correlation)를 이용하였다. HRQOL에 영향을 미치는 요인들을 분석하 기 위해서 HRQOL을 종속변수로 선정하고 인구사회학적 특성 및 구강건강 상태, 구강건강서비스 이용을 독립변수로 설정하여 다중회귀분석(multiple regression)을 실시하였다. 통계 패키지 는 SPSS Statistics 21.0 (IBM Corp., Armonk, NY, USA)을 이 용하여 분석하였다. 통계적 유의수준은 $p<0.05$ 로 설정하였다. 


\section{결 과}

\section{인구사회학적 특성과 건강 관련 삶의 질(EQ-5D) 수준}

성별에서는 남성이 여성보다 HRQOL이 높았고, 유의한 차 이가 있었다 $p<0.001)$. 연령에서도 60 대가 70대, 80대보다 삶의 질이 높았으며 유의한 차이를 보였다 $(p<0.001)$. 교육수 준에서는 고등학교 졸업 이상에서 삶의 질 수준이 높았으며 $(p$ $<0.001$ ), 월수입의 경우 100-200만원 사이일 때가 삶의 질 수 준이 높았다 $(p<0.001)$. 경제활동을 하는 경우 삶의 질 수준이 높았으며 $(p<0.001)$, 음주를 하는 경우 삶의 질 수준이 높았다 $(p<0.001)$ (Table 1).

\section{구강건강과 구강건강서비스 이용과 건강 관련 삶의 질(EQ-} 5D) 수준

주관적 구강건강에 대하여 좋다고 생각할 때 삶의 질이 높 았고 $(p<0.001)$, 저작문제가 없을 때 삶의 질이 높았다 $(p$ $<0.001)$. 발음 문제가 없는 경우 삶의 질이 높았고 $(p<0.001)$, 필요 치과치료 미수진이 없는 경우 역시 삶의 질 수준이 높았다 $(p<0.001)$.

구강검진과 스케일링 경험은 HRQOL에 대해 유의한 차이가 없었다(Table 2).

\section{건강 관련 삶의 질(EQ-5D)과 관련 변수 간의 상관관계}

구강건강 상태, 구강서비스 이용과 $\mathrm{HRQOL}(\mathrm{EQ}-5 \mathrm{D})$ 의 상관 관계를 살펴보았을 때, $\mathrm{HRQOL}$ (EQ-5D)은 주관적 구강건강 상 태( $\mathrm{r}=0.169, p<0.001)$, 저작 문제 $(\mathrm{r}=0.215, p<0.001)$, 발음 문

Table 1. Distribution of health-related EQ-5D levels according to general characteristics $(\mathrm{N}=2,671)$

\begin{tabular}{|c|c|c|c|}
\hline \multirow{2}{*}{ Characteristic } & \multicolumn{2}{|c|}{ Quality of life (EQ-5D) } & \multirow{2}{*}{$p$-value } \\
\hline & The elderly (\%) & Mean \pm SD & \\
\hline Gender & & & $<0.001$ \\
\hline Male & $324(12.1)$ & $0.82 \pm 0.16$ & \\
\hline Female & $2,347(87.9)$ & $0.77 \pm 0.16$ & \\
\hline Age (y) & & & $<0.001$ \\
\hline $65-69$ & $361(13.5)$ & $0.86 \pm 0.11^{\mathrm{a}}$ & \\
\hline $70-79$ & $1,329(49.8)$ & $0.79 \pm 0.15^{\mathrm{a}}$ & \\
\hline$\geq 80$ & $981(36.7)$ & $0.74 \pm 0.17^{\mathrm{b}}$ & \\
\hline Education level & & & $<0.001$ \\
\hline No education & $1,384(51.8)$ & $0.76 \pm 0.17^{\mathrm{b}}$ & \\
\hline Elementary school & $1,058(39.6)$ & $0.80 \pm 0.14^{\mathrm{b}}$ & \\
\hline Middle school & $127(4.8)$ & $0.83 \pm 0.14^{\mathrm{b}}$ & \\
\hline$\geq$ High school & $102(3.8)$ & $0.84 \pm 0.18^{\mathrm{a}}$ & \\
\hline Household income (won) & & & $<0.001$ \\
\hline$<500,000$ & $1,750(65.5)$ & $0.76 \pm 0.17^{\mathrm{b}}$ & \\
\hline $500,000-1,000,000$ & $763(28.6)$ & $0.81 \pm 0.14^{\mathrm{b}}$ & \\
\hline $1,000,000-2,000,000$ & $131(4.9)$ & $0.85 \pm 0.11^{\mathrm{a}}$ & \\
\hline$\geq 2,000,000$ & $27(1.0)$ & $0.83 \pm 0.12^{\mathrm{b}}$ & \\
\hline Economy activity & & & $<0.001$ \\
\hline Yes & $951(35.6)$ & $0.83 \pm 0.12$ & \\
\hline No & $1,720(64.4)$ & $0.78 \pm 0.16$ & \\
\hline Current smoking & & & 0.062 \\
\hline Yes & $100(3.7)$ & $0.81 \pm 0.17$ & \\
\hline No & $2,571(96.3)$ & $0.78 \pm 0.17$ & \\
\hline Alcohol drinking & & & $<0.001$ \\
\hline Yes & $794(29.7)$ & $0.82 \pm 0.13$ & \\
\hline No & $1,877(70.3)$ & $0.76 \pm 0.17$ & \\
\hline
\end{tabular}

SD, standard deivation; EQ-5D, European Quality of Life-5 dimension. $\mathrm{a}>\mathrm{b}$. 
제 $(\mathrm{r}=0.215, p<0.001)$, 구강검사 $(\mathrm{r}=0.078, p<0.001)$, 스케일 링 경험 $(\mathrm{r}=0.073, p<0.001)$, 필요 치과치료 미수진 $(\mathrm{r}=-0.163$, $p<0.001)$ 과 상관관계가 있었다. HRQOL과 주관적 구강건강 상 태, 저작 문제, 발음 문제, 구강검사, 스케일링 경험에서는 양의 상관관계를, 필요 치과치료 미수진은 음의 상관관계로 나타났 다(Table 3).

Table 2. Distribution of health-related EQ-5D levels according to oral health status and dental care utilization $(\mathrm{N}=2,671)$

\begin{tabular}{|c|c|c|c|}
\hline \multirow{2}{*}{ Variable } & \multicolumn{2}{|c|}{ Quality of life (EQ-5D) } & \multirow{2}{*}{$p$-vaule } \\
\hline & The elderly (\%) & Mean \pm SD & \\
\hline \multicolumn{4}{|l|}{ Oral health status } \\
\hline Perceived oral health & & & $<0.001$ \\
\hline Good & $281(10.5)$ & $0.83 \pm 0.14^{\mathrm{a}}$ & \\
\hline Fair & $555(20.8)$ & $0.82 \pm 0.13^{\mathrm{b}}$ & \\
\hline Poor & $1,835(68.7)$ & $0.76 \pm 0.17^{\mathrm{b}}$ & \\
\hline Chewing problem & & & $<0.001$ \\
\hline Yes & $1,605(60.1)$ & $0.75 \pm 0.17^{\mathrm{b}}$ & \\
\hline Fair & $307(11.5)$ & $0.81 \pm 0.13^{\mathrm{b}}$ & \\
\hline No & $759(28.4)$ & $0.83 \pm 0.13^{\mathrm{a}}$ & \\
\hline Speaking problem & & & $<0.001$ \\
\hline Yes & $696(26.1)$ & $0.72 \pm 0.20^{\mathrm{b}}$ & \\
\hline Fair & $416(15.6)$ & $0.77 \pm 0.15^{\mathrm{b}}$ & \\
\hline No & $1,559(58.4)$ & $0.81 \pm 0.13^{\mathrm{a}}$ & \\
\hline \multicolumn{4}{|l|}{ Dental care utilization } \\
\hline Oral health examination & & & 0.064 \\
\hline Yes & $322(12.1)$ & $0.81 \pm 0.15$ & \\
\hline No & $2,349(87.9)$ & $0.77 \pm 0.16$ & \\
\hline Scaling experience & & & 0.076 \\
\hline Yes & $235(8.8)$ & $0.82 \pm 0.14$ & \\
\hline No & $1,264(56.1)$ & $0.78 \pm 0.16$ & \\
\hline Unmet dental needs & & & $<0.001$ \\
\hline Yes & $655(24.5)$ & $0.73 \pm 0.18$ & \\
\hline No & $2,016(75.5)$ & $0.79 \pm 0.15$ & \\
\hline
\end{tabular}

SD, standard deviation; EQ-5D, European Quality of Life-5 dimension.

$\mathrm{a}>\mathrm{b}$.

\section{건강 관련 삶의 질(EQ-5D)에 관련된 요인}

노인의 HRQOL에 영향을 미치는 요인을 파악하기 위하여 일 반적 특성, 구강건강상태, 구강서비스 이용 변수를 모형에 투입 하여 다중회귀분석을 실시하였다(Table 4). 회귀분석을 실시하 기 전에 독립변수들 사이의 다중공선성을 살펴보았다. 독립변 수들 간의 상관관계는 0.00 에서 0.56 으로 나타났다. 모든 변수 에서 공차한계는 0.10 보다 높은 수준이었다. 분산팽창 요인은 1.019 에서 1.125 사이로 독립변수 간의 상관관계로 인한 연구 모형 왜곡의 가능성이 낮게 나타난다고 보았다. 잔차분석에서 Durbin-Watson 통계량은 1.946으로 모형의 오차항간 자기상 관성이 없는 것으로 잔차의 등분성과 정규분포성 가정을 만족 한다고 보았다.

모델 I 은 인구사회학적 특성, 모델 III는 구강건강 상태, 모 델 III는 구강건강서비스 이용을 차례대로 투입하여 모델에 미 치는 변수의 영향력을 파악하였다. 분석결과 모델 I 은 남성 일수록 $(\beta=0.085, p=0.005)$, 연령이 낮을수록 $(\beta=-0.191, p$ $<0.001)$, 경제활동을 할수록 $(\beta=0.133, p<0.001)$ 삶의 질이 높았으며, 설명력은 $11.8 \%$ 였다. 모델 II는 모델 I 의 변수에 구 강건강 상태를 투입하였다. 분석결과는 남성일수록 $(\beta=0.082$, $p=0.005)$, 연령이 낮을수록 $(\beta=-0.152, p<0.001)$, 경제활동을 할수록 $(\beta=0.118, p<0.001)$, 저작 문제가 없을수록 $(\beta=-0.128$, $p<0.001)$, 발음 문제가 없을수록 $(\beta=-0.081, p=0.002)$ 삶의 질 이 높았으며, 설명력은 $15.5 \%$ 였다. 모델 III은 모델 II의 변수에 구강건강서비스 이용 변수를 투입하였다. 분석결과는 남성일수 록 $(\beta=0.074, p=0.011)$, 연령이 낮을수록 $(\beta=-0.158, p<0.001)$, 경제활동을 할수록 $(\beta=0.114, p<0.001)$, 저작 불편 $(\beta=-0.103$, $p=0.001)$, 발음 문제가 없을수록 $(\beta=-0.073, p=0.006)$, 구강검 진을 받을수록 $(\beta=0.050, p=0.043)$, 필요 치과진료 미수진이 없 을수록 $(\beta=-0.110, p<0.001)$ 삶의 질이 높았으며, 설명력은 $16.8 \%$ 였다(Table 4).

Table 3. Correlations of related variables with health-related EQ-5D

\begin{tabular}{lccccc}
\hline & $\begin{array}{c}\text { Perceived oral } \\
\text { health }\end{array}$ & $\begin{array}{c}\text { Chewing } \\
\text { problem }\end{array}$ & $\begin{array}{c}\text { Speaking } \\
\text { problem }\end{array}$ & $\begin{array}{c}\text { Oral health } \\
\text { examination }\end{array}$ & $\begin{array}{c}\text { Scaling } \\
\text { experience }\end{array}$ \\
\hline Chewing problem & $0.559^{\mathrm{b}}$ & & & & \\
Speaking problem & $0.333^{\mathrm{b}}$ & $0.475^{\mathrm{b}}$ & & & \\
Oral health examination & $0.043^{\mathrm{b}}$ & $0.074^{\mathrm{b}}$ & 0.059 & & \\
Scaling experience & $0.119^{\mathrm{b}}$ & $0.148^{\mathrm{b}}$ & $0.133^{\mathrm{b}}$ & $0.261^{\mathrm{b}}$ & $-0.086^{\mathrm{b}}$ \\
Unmet dental needs & $-0.192^{\mathrm{b}}$ & $-0.241^{\mathrm{b}}$ & $-0.167^{\mathrm{b}}$ & $-0.042^{\mathrm{a}}$ & $0.073^{\mathrm{b}}$ \\
EQ-5D & $0.169^{\mathrm{b}}$ & $0.215^{\mathrm{b}}$ & $0.215^{\mathrm{b}}$ & $0.078^{\mathrm{b}}$ & $-0.163^{\mathrm{b}}$ \\
\hline
\end{tabular}

EQ-5D, European Quality of Life-5 dimension.

${ }^{\mathrm{a}} \mathrm{p}<0.05,{ }^{\mathrm{b}} \mathrm{p}<0.001$. 
Table 4. Related factors of health-related quality of life assessment by the EQ-5D

\begin{tabular}{|c|c|c|c|c|c|c|c|c|c|}
\hline \multirow{2}{*}{ Variable } & \multicolumn{3}{|c|}{ Model I } & \multicolumn{3}{|c|}{ Model II } & \multicolumn{3}{|c|}{ Model III } \\
\hline & $\beta$ & $\mathbf{t}$ & $p$-value & $\beta$ & $\mathbf{t}$ & $p$-value & $\beta$ & $\mathbf{t}$ & $p$-value \\
\hline Gender & 0.085 & 2.841 & 0.005 & 0.082 & 2.787 & 0.005 & 0.074 & 2.534 & 0.011 \\
\hline Age & -0.191 & -6.987 & $<0.001$ & -0.152 & -5.579 & $<0.001$ & -0.158 & -5.759 & $<0.001$ \\
\hline Education level & -0.056 & -2.088 & 0.067 & -0.035 & -1.340 & 0.180 & -0.032 & -1.227 & 0.220 \\
\hline Economy activity & 0.133 & 5.137 & $<0.001$ & 0.118 & 4.636 & $<0.001$ & 0.114 & 4.539 & $<0.001$ \\
\hline Current smoking & -0.009 & -0.356 & 0.722 & -0.001 & -0.043 & 0.965 & 0.009 & 0.348 & 0.728 \\
\hline Alcohol drinking & 0.087 & 3.429 & 0.121 & 0.078 & 3.137 & 0.326 & 0.077 & 3.102 & 0.352 \\
\hline Perceived oral health & & & & -0.054 & -1.859 & 0.063 & -0.047 & -1.607 & 0.108 \\
\hline Chewing problem & & & & -0.128 & -4.183 & $<0.001$ & -0.103 & -3.341 & 0.001 \\
\hline Speaking problem & & & & -0.081 & -3.083 & 0.002 & -0.073 & -2.771 & 0.006 \\
\hline Oral health examination & & & & & & & 0.050 & 2.027 & 0.043 \\
\hline Scaling experience & & & & & & & -0.030 & -1.176 & 0.240 \\
\hline Unmet dental needs & & & & & & & -0.110 & -4.382 & $<0.001$ \\
\hline $\mathrm{F}(\mathrm{p})$ & \multicolumn{3}{|c|}{$32.091(<0.001)$} & \multicolumn{3}{|c|}{$30.445(<0.001)$} & \multicolumn{3}{|c|}{$25.160(<0.001)$} \\
\hline Adjusted $\mathrm{R}^{2}$ & \multicolumn{3}{|c|}{0.118} & \multicolumn{3}{|c|}{0.155} & \multicolumn{3}{|c|}{0.168} \\
\hline
\end{tabular}

EQ-5D, European Quality of Life-5 dimension.

Dummy variable: gender, male/female; education, no education/education; economy activity, yes/no; current smoking, yes/no; alcohol drinking, yes/no; perceived oral health, healthy/unhealthy; chewing problem, yes/no; speaking problem, yes/no; oral health examination, yes/no; scaling experience, yes/no; unmet dental needs, yes/no.

\section{고 찰}

본 연구에서는 독거노인의 구강건강, 구강건강서비스 이용과 $\mathrm{HRQOL}$ (EQ-5D) 간의 관련성을 살펴보고자 시행하였다.

$\mathrm{HRQOL}$ 과 인구사회학적 특성을 분석한 결과, 성별에서는 여 자보다 남자가 HRQOL이 높았고, 기존의 연구와 유사하였다 $[13,14]$. 교육 수준과 소득 수준이 높을수록 HRQoL이 높았으며 이는 선행연구 결과와 같았다[15,16]. 교육 수준이 높은 사람의 경우 비교적 높은 사회적 직위 및 경제 활동으로 생활에 여유가 있고, 소득수준이 높은 경우 필요에 따라 자신에게 쓸 수 있는 재화가 비교적 여유로워 삶의 질이 높은 것으로 생각한다.

$\mathrm{HRQOL}$ 과 구강건강 상태를 분석한 결과, 저작 불편과 말하기 불편은 삶의 질을 낮추는 요인으로 나타나 기존 연구결과와 일 치했다. 치아우식증과 치주질환의 진행에 따라 식사 및 음식물 섭취 시 저작에 문제를 일으켜 궁극적으로 저작 불편을 야기하 며, 이는 치아상실, 구취, 발음 불편 등의 원인이 되기 때문이라 고 보았다[17]. 따라서 전신건강을 유지하는 데에 있어 구강건 강은 중요한 역할을 하며 삶의 질 향상에 중요하게 영향을 미친 다는 것을 확인하였다. 구강건강 상태를 보다 나은 방향으로 개 선하고 증진시킬 수 있도록 독거노인의 구강건강을 위한 구강 보건 예방 및 교육프로그램 개발과 더불어 반복 교육이 필요할 것으로 생각한다. 스케일링 경험에 따른 삶의 질의 경우 유의한 결과가 나오지 않은 것은 스케일링 경험 응답이 치아가 있는 독 거노인으로 한정되었고, 치아가 있는 독거노인 중에서도 적은
수의 독거노인(전체 독거노인 중 8.8\%)만 스케일링 경험이 있었 기 때문이다. 독거노인의 낮은 스케일링 경험 특성을 고려하여, 구강건강 개선을 위한 스케일링의 중요성에 대하여 교육 및 홍 보가 적극적으로 이루어져야 할 것으로 생각한다. 추후 치아가 없는 독거노인과 치아가 있는 독거노인의 삶의 질과 관련된 요 인에 대해 심층적인 연구가 이루어져야 할 것이다.

여러 가지 요인(인구사회학적 특징, 구강건강 상태 및 구강건 강서비스 이용) 중 건강 관련 삶의 질에 영향을 미치는 요인들을 확인하기 위해서 회귀분석을 실시한 결과를 살펴보면, 연령이 증가할수록 HRQOL이 낮았으며 교육수준, 소득수준이 높을수 록 $\mathrm{HRQOL}$ 이 높아진 것을 알 수 있다. 이는 기존 연구결과에서 연령이 낮아질수록 교육수준이 높고, 경제활동을 하고 있을 때 HRQOL이 높았다고 보고해 본 연구결과와 같음을 확인하였다 $[13,18]$. 본 연구에서는 저작 불편과 발음 불편이 있을 때 건강 관련 삶의 질이 낮게 나타났다. 기존의 연구에서 저작 기능 저 하가 삶의 질에 부정적인 영향을 미친다는 내용과 일치하는 결 과이다[17,19]. 구강건강서비스 이용에서는 구강검진을 받았을 때, 필요 치과치료 미수진이 없을 때 HRQOL 점수가 높았다. 구 강검진을 받고 필요 치과치료 미수진이 없는 것은 꾸준히 구강 건강 관리를 하고 있는 상태이기 때문에 그렇지 않은 경우에 비 하여 구강건강 상태가 좋은 상태라고 볼 수 있다. 기존의 연구에 서 저작 문제가 있는 대상자의 치과진료 미수진률이 2.29배 높 게 나타났다. 이는 자신의 구강건강에 심각한 문제가 생겼지만 치과에 가지 않는 것으로 이해할 수 있으며 시간이 지연된 만큼 
치료비용 부담이 가장 큰 이유로 추정되며 이것은 건강 관련 삶 의 질에 크게 영향을 미친다고 보았다[20,21]. 따라서 증세가 경 미할 때 예방적 치료를 받고, 적절한 시기에 정기검진을 받을 수 있도록 필요성에 대해 적극적인 홍보 및 교육이 필요하다고 판 단된다. 기존 연구결과 일반 건강수준은 개인의 구강건강 수준 과 관련이 높으며, 일반 건강수준이 높을수록 개인의 구강건강 수준도 높다고 보고하였다[22]. 이는 구강건강이 HRQOL과 연 관성이 있는 것으로 볼 수 있으며, 구강건강은 전신건강에 영향 을 미칠 수 있으므로 독거노인의 구강건강의 증진 및 예방 교육 프로그램에 이러한 내용을 포함한 삶의 질을 증진시킬 수 있는 독거노인 맞춤 구강보건사업이 필요하다고 생각한다.

본 연구의 제한점으로는 지역사회건강조사는 단면조사 연구 로 구강건강 상태, 구강건강서비스 이용과 $\mathrm{HRQOL}$ (EQ-5D)의 인과관계를 명확하게 설명할 수 없었으며, 전라남도 22 개 지역 으로 한정하였다. 또한 이차자료를 사용하였기 때문에 HRQoL (EQ-5D)에 영향을 주는 다양한 독립변수들을 추가하지 못해 모 델의 설명력이 낮게 나타난 것으로 보인다. 추후 $\mathrm{HRQOL}$ 와 관련 된 요인으로 구강건강 상태 및 구강건강서비스 이용에 관한 심 층연구가 필요할 것으로 생각한다. 이러한 제한점이 있음에도 $\mathrm{HRQOL}$ 과 구강건강 및 구강건강서비스 이용과 관련한 영향을 규명하여 독거노인의 건강 유지 및 증진을 위한 구강건강교육 프로그램의 기초 자료를 제공하는 데 의의가 있다.

\section{CONFLICTS OF INTEREST}

The authors declare that they have no competing interests.

\section{ORCID}

\author{
Seong Hyeon Chae \\ https://orcid.org/0000-0003-1969-0673 \\ Chun-Bae Kim \\ https://orcid.org/0000-0002-1979-6833
}

\section{REFERENCES}

1. Statistics Korea. Life expectancy and disability adjusted life expectancy [Internet]. Daejeon: Statistics Korea; 2018 [cited 2018 Nov 10]. Available from: http://www.index. go.kr/unify/idx-info.do?idxCd=4035.

2. Korea Institute for Health and Social Affairs. 2014 survey of the elderly. Sejong: Korea Institute for Health and Social Affairs; 2014 December. Report No.: 2014-61.

3. Disease Statistics. Healthcare Bigdata Hub [Internet]. Won- ju: Healthcare Insurance Review \& Assessment Service; 2010 [cited 2018 Nov 10]. Available from: http://opendata. hira.or.kr/op/opc/olapHifrqSickInfo.do.

4. Locker D, Slade G. Association between clinical and subjective indicators of oral health status in an older adult population. Gerodontology 1994;11:108-114. doi: 10.1111/j.1741-2358.1994.tb00116.x.

5. Cushing AM, Sheiham A, Maizels J. Developing sociodental indicators-the social impact of dental disease. Community Dent Health 1986;3:3-17.

6. Albandar JM, Brunelle JA, Kingman A. Destructive periodontal disease in adults 30 years of age and older in the United States, 1988-1994. J Periodontol 1999;70:13-29. doi: 10.1902/jop.1999.70.1.13.

7. Park KS, Kim MS. The impact of changes in household living arrangements on the changes in poverty rate among elderly people in South Korea. Korean J Soc 2016;50:221253. doi: 10.21562/kjs.2016.02.50.1.221.

8. Yoon MS. The study on the relationship of psychosocial factors, problem drinking on quality of life for the elderly in urban and rural areas. J Welf Aged 2007;38:281-310.

9. Jo MW, Lee SI. [General population time trade-off values for 42 EQ-5D health states in South Koreal. J Prev Med Public Health 2007;40:169-176. Korean. doi: 10.3961/ jpmph.2007.40.2.169.

10. Zack MM, Moriarty DG, Stroup DF, Ford ES, Mokdad AH. Worsening trends in adult health-related quality of life and self-rated health-United States, 1993-2001. Public Health Rep 2004;119:493-505. doi: 10.1016/j.phr.2004.07.007.

11. Wallander JL, Varni JW. Effects of pediatric chronic physical disorders on child and family adjustment. J Child Psychol Psychiatry 1998;39:29-46. doi: 10.1111/14697610.00302.

12. Brooks R, Rabin R, de Charro F. The measurement and valuation of health status using EQ-5D: a European perspective. Evidence from the EuroQol BIOMED Research Program. Dordrecht: Kluwer Academic Publisher; 2005.

13. Moon BA, Jeong SR, Jang JY, Kim KY. Health-related quality of life by oral health behavior and oral health status for the middle-aged people. J Korean Soc Dent Hyg 2015;15:197-204. doi: 10.13065/jksdh.2015.15.02.197.

14. Shin HS, Kim HD. Association between the number of existing permanent teeth and health-related quality of life (EuroQol-5 Dimension) among adults: findings from the fifth Korea National Health and Nutrition Examination Surveys, 2012. J Korean Acad Oral Health 2015;39:303-310. doi: 10.11149/jkaoh.2015.39.4.303.

15. Breeze E, Jones DA, Wilkinson P, Latif AM, Bulpitt CJ, Fletcher AE. Association of quality of life in old age in Britain with socioeconomic position: baseline data from a randomised controlled trial. J Epidemiol Community Health 2004;58:667-673. doi: 10.1136/jech.2003.014035.

16. Kim SY, Sohn S. Factors related to health related qual- 
ity of life in rural elderly women. J Korean Gerontol Nurs 2012;14:91-98.

17. Choi ES, Lyu J, Kim HY. Association between oral health status and health related quality of life (EuroQoL-5 Dimension). J Dent Hyg Sci 2015;15:480-487. doi: 10.17135/ jdhs.2015.15.4.480.

18. Yoon MH. Association between oral health and healthrelated quality of life in adults [Thesis]. Seoul: Korea University; 2008.

19. Song KH. A study on the evaluation of health- and oral health- realated quality of life in Korean adults [dissertation]. Seoul: Hanyang University; 2007.
20. Kim YH, Lee JH. Relationship between unmet dental needs and the general and oral health status of adults. J Korean Acad Oral Health 2018;42:16-23. doi: 10.11149/ jkaoh.2018.42.1.16.

21. Kim YH, Lee JH. The relationship of quality of healthrelated life with the status of oral health in adults. J Korean Acad Oral Health 2016;40:165-170. doi: 10.11149/ jkaoh.2016.40.3.165.

22. Lee IC, Shieh TY, Yang YH, Tsai CC, Wang KH. Individuals' perception of oral health and its impact on the healthrelated quality of life. J Oral Rehabil 2007;34:79-87. doi: 10.1111/j.1365-2842.2006.01694.x. 